\title{
Effect of vitamin A supplementation on haemoglobin and vitamin $A$ levels during pregnancy
}

\author{
BY MEENA PANTH, VEENA SHATRUGNA, P. YASODHARA \\ AND B. SIVAKUMAR* \\ National Institute of Nutrition, Indian Council of Medical Research, Jamai Osmania PO, \\ Hyderabad-500 007, India
}

(Received 15 February 1989 - Accepted 16 February 1990)

\begin{abstract}
About 450 pregnant women from a low-income group were recruited to study the effect of vitamin $A$ supplementation on plasma vitamin $A$ levels in the mother and cord and on the birth weights of the neonates. Results showed that supplementation with $1800 \mu \mathrm{g}$ vitamin $\mathrm{A} / \mathrm{d}$ for more than 12 weeks prevented the decline in plasma vitamin $A$ that otherwise occurs during the last few weeks of pregnancy. This improvement in maternal values for vitamin $A$ at a critical time of development favourably affected availability to the fetus, as reflected by the marked elevation in cord levels. Supplementation for a period of 12 weeks was found to be sufficient, since subsequent discontinuation did not alter the beneficial response. Apart from increasing maternal and cord vitamin A levels, vitamin A supplementation along with iron prevented, in this study, the significant decline in haemoglobin occurring at 26-28 weeks of gestation. The birth weights were not altered by vitamin A supplementation.
\end{abstract}

Vitamin A supplementation: Pregnancy : Haemoglobin

Earlier studies have focused attention on the changes in vitamin A status during pregnancy, most of them reporting a decline in plasma vitamin A levels in the third trimester (Bodansky et al. 1943; Basu \& Arulanantham, 1973; Ette \& Ibeziako, 1984) with poor fetal stores and low cord vitamin A (Venkatachalam et al. 1962; Baker et al. 1975; Shah et al. 1987). Increased incidence of dark-adaptation failure and night blindness associated with low dietary intake of vitamin A by pregnant women has been reported by Dixit (1966) and Gopalan \& Jayarao (1972).

To prevent this decrease in serum vitamin A during pregnancy and, thus, to minimize the adverse effects, if any, a few attempts have been made to supplement the mother with vitamin A during pregnancy. Due to differences in the experimental designs used and the socio-economic status of the study population, definite conclusions could not be drawn from the previous investigations.

Bearing all these facts in mind, a detailed study was conducted (1) to investigate the changes in circulating levels of carotenoids and vitamin A with gestation, (2) to analyse the effect of supplementation on certain maternal variables like haemoglobin, (3) to observe the effects of $(a)$ starting supplementation at different gestational ages, $(b)$ the duration of supplementation, and $(c)$ the subsequent discontinuation of supplementation, on the plasma levels of vitamin $\mathrm{A}$ in the mother throughout gestation and in the cord at the time of delivery, and also the birth weight of the neonates. Some of the findings described here were reported earlier as preliminary observations (Panth et al. 1986).

\footnotetext{
* For reprints.
} 


\section{MATERIALS AND METHODS}

The study population comprised 450 women attending antenatal clinics on an out-patient basis in two local hospitals during the years 1983-6. Most of them belonged to a low socioeconomic group, and were registered at different gestational ages. For comparison, blood samples were also collected from eight non-pregnant, non-lactating (NPNL) women. After collecting the initial blood samples, the women were assigned to either a vitamin A-supplemented or an unsupplemented group. The former was further divided into three subgroups based on their gestational age at recruitment (12-14, 16-18 and 20-24 weeks). They received tablets containing $1800 \mu \mathrm{g}$ specially prepared vitamin A (Roche India Ltd) either for periods of 6-10 weeks or for periods of more than 12 weeks duration. The women from both groups were given iron tablets $(60 \mathrm{mg}$ ferrous sulphate), which is the usual practice of the hospital and which also served as a placebo in the control group. They were clinically examined once monthly and given sufficient tablets for the intervening period. The regularity of pill intake was ascertained at the time of each visit.

Blood samples were collected at least once in each trimester of pregnancy. Wherever possible blood samples were taken from the mother and the cord at the time of delivery and the birth weights of the newborn were recorded. Haemoglobin was estimated by the cyanmethaemoglobin method (Dacie \& Lewis, 1975). Plasma was separated and stored at $-20^{\circ}$. Carotenoids and vitamin A levels were estimated by a colorimetric method (Tiews \& Zentz, 1967), within $10 \mathrm{~d}$ of the collection of the sample.

\section{RESULTS}

Of the 450 pregnant women recruited, only $202(45 \%)$ women who had contributed a minimum of one sample in the second or third trimester, or both, were considered for analysis in a cross-sectional and semi-longitudinal manner.

\section{Changes in plasma carotenoids and vitamin A levels during pregnancy}

The mean carotenoid concentration in the plasma of NPNL women was 845 (SE 104) $\mu \mathrm{g} / \mathrm{l}$. Similar levels $(\mu \mathrm{g} / \mathrm{l})$ were observed in pregnant women at $12-14$ weeks (862 (SE 64), $n$ 16) and, thereafter, they showed a rise (1040 (SE 70), $n$ 30) at 24-26 weeks and reached a maximum value (1108 (SE 53), $n$ 39) at 34-38 weeks of gestation. This final value was significantly higher than that obtained at $12-14$ weeks.

The mean plasma vitamin A level $(\mu \mathrm{g} / 1)$ was significantly lower (275 (SE 15)) at 12-14 weeks of pregnancy (Table 1) than that of the NPNL women (407 (SE 34)). The levels increased with advancing gestation, reaching a peak at 24-26 weeks (347 (SE $16 \mu \mathrm{g} / \mathrm{l})$, and then declining to 295 (SE 13) $\mu \mathrm{g} / 1$ at $34-38$ weeks. The peak plasma vitamin A concentration was significantly higher than that at $12-14 / 34-38$ weeks.

Analysis of samples collected from the same individuals indicated a similar trend. There was a significant increase in plasma vitamin A at 28-32 weeks compared with that at 12-14 weeks $(n$ 11). Similarly, the values observed at $24-26$ weeks were significantly higher than those at 16-18 weeks ( $n$ 15). There was a significant decrease in the vitamin A levels during the third trimester, the values being significantly lower at 34-38 weeks than those at 28-32 weeks $(n 24)$. These observations confirm the results obtained on a cross-section basis.

\section{Effect of supplementation}

Plasma carotenoid levels were unaltered by vitamin A supplementation at all gestational ages. In view of the changes in plasma vitamin A during gestation in the unsupplemented women, the values for the vitamin A-supplemented women were compared with the 


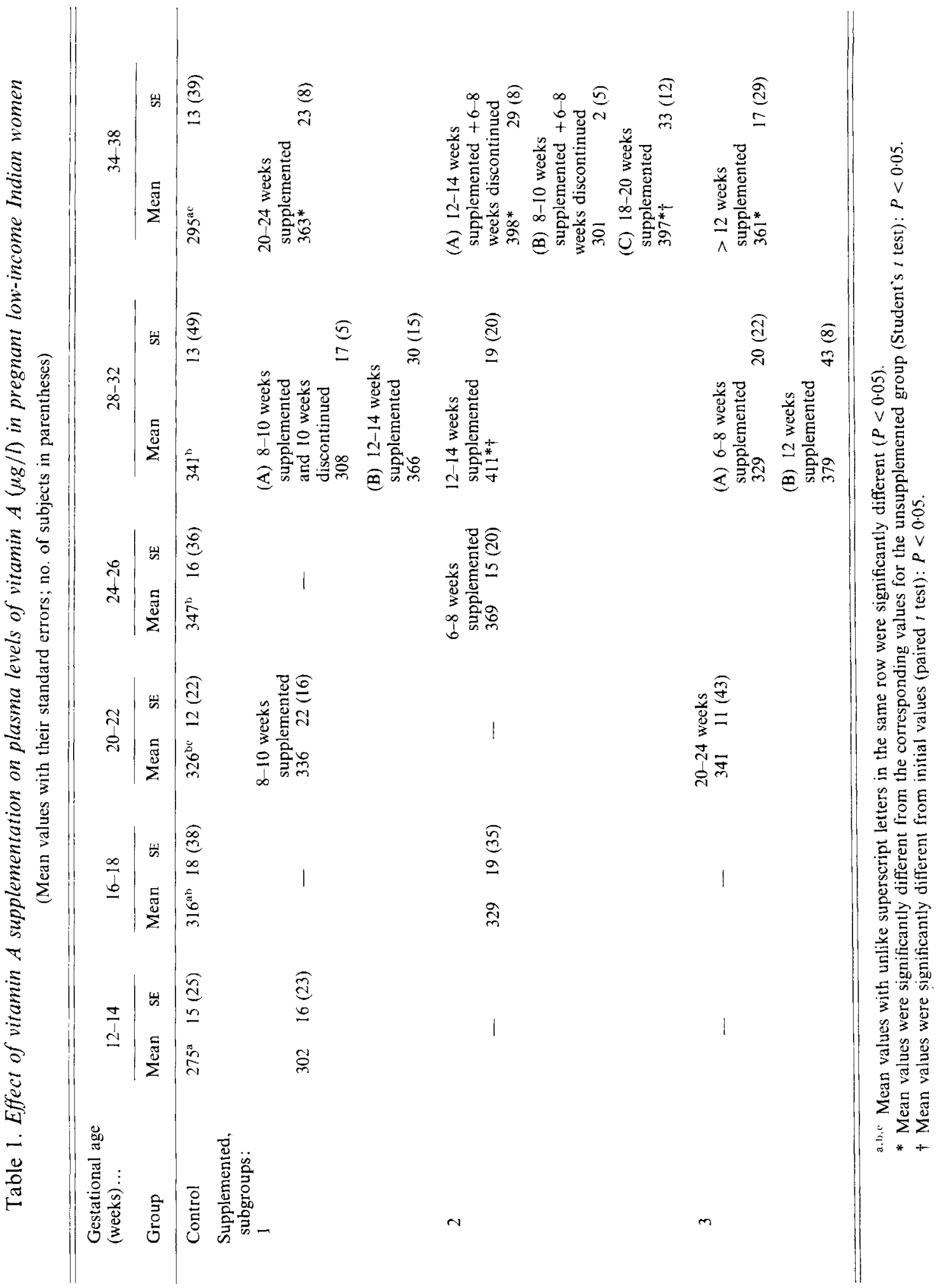


corresponding values for the control group at the same gestational age on a cross-sectional basis (Table 1).

Results showed that irrespective of the gestational age at which the supplementation was started and its duration (short or long duration), the broad peak of plasma vitamin A attained between 20 and 26 weeks was not significantly different from that of the controls.

Similarly, in each of the subgroups (groups 1, 2A, 2C and 3) at 34-38 weeks of gestation, supplementation for at least 12 weeks had significantly elevated the plasma levels compared with the values observed in the controls.

Supplementation for a period of 8-10 weeks followed by discontinuation for $6-8$ weeks (group 2B) was not adequate to prevent the normal fall in vitamin A towards term. Supplementation for 12-14 weeks under similar conditions of withdrawal was sufficient to maintain the values at term higher than in the untreated group (2A) or was sufficient to maintain the concentration similar to that of groups receiving supplements for a period of 20-24 weeks (groups 1 and 3) or 18-20 weeks (group 2C).

When the findings were analysed in a semi-longitudinal manner, it was observed that the plasma vitamin A values at 28 weeks were significantly higher than those at 16 weeks $(n 19)$. This change is similar to that observed in unsupplemented women. However, thereafter a significant difference was observed between the two groups. The supplemented women continued to show a significant increase at $34-38$ weeks unlike the control group.

\section{Effect of supplementation on perinatal findings}

Since gestational age at which supplementation begins did not modify the plasma vitamin A levels towards term, and the number of women who were admitted for delivery at the hospital was small, values from all the supplemented subgroups were pooled. The effects of short ( $8-10$ weeks)- and long ( $>12$ weeks)-term supplementation on perinatal variables such as plasma vitamin $A$ levels in mother and cord at the time of delivery, and the birth weights of neonates were determined.

The results presented in Table 2 show that in the untreated group the mean cord vitamin A $(\mu \mathrm{g} / 1)$ was 135 (SE 15), and this was significantly lower than that of their respective maternal samples ( 267 (SE 30) $\mu \mathrm{g} / 1)$ at the time of delivery. Irrespective of the duration of treatment, the cord levels of vitamin A of the supplemented groups were higher than those of the unsupplemented group. However, only the increase with longer duration of treatment (232 (SE 29) $\mu \mathrm{g} / 1$ ) was statistically significant. Due to these increases, the differences between maternal and cord levels of treated mothers were confined to the supplemented groups.

The carotenoid levels were lower in the cord than in the mother and showed no significant difference between the three groups.

The mean birth weight of the neonates born to unsupplemented women was 2.68 (SE 0.093) kg (Table 2). Supplementation for 8-10 weeks $(2.70$ (SE 0.078) kg) or more than 12 weeks $(2 \cdot 86(\mathrm{SE} 0 \cdot 125) \mathrm{kg})$ did not affect birth weight significantly.

\section{Effect of supplementation on haemoglobin levels in pregnancy}

Changes in haemoglobin levels are shown in Table 3 . When only the basal values for all unsupplemented and supplemented women were considered, there was a progressive decline in mean haemoglobin values (g/l) from 114 (SE 2.9) at 12 weeks to reach the lowest concentration of 96 (SE 2.5) at 26-28 weeks. Thereafter, the haemoglobin concentration progressively increased towards term $(111$ (SE 3.4) g/l). The haemoglobin values for women receiving supplements were compared with the basal levels at the same gestational age in a cross-sectional manner. In the women receiving Fe tablets there was an increase, though not statistically significant, at 26-28 weeks of gestation (104 (SE 3.9) g/1). However, when 
Table 2. Effect of vitamin A supplementation of low-income Indian women on maternal and cord plasma carotenoids and vitamin $A$ levels at delivery and on birth weights of neonates

(Mean values with their standard errors; no. of subjects in parentheses)

\begin{tabular}{|c|c|c|c|c|c|c|}
\hline \multirow[b]{3}{*}{ Variable } & & & \multicolumn{4}{|c|}{ Vitamin A-supplemented } \\
\hline & \multicolumn{2}{|c|}{ Control } & \multicolumn{2}{|c|}{$8-10$ weeks } & \multicolumn{2}{|c|}{$>12$ weeks } \\
\hline & Mean & SE & Mean & SE & Mean & $\mathrm{SE}$ \\
\hline Birth wt $(\mathrm{kg})$ & \multicolumn{2}{|c|}{$(12)$} & $2 \cdot 70^{\text {a }}$ & 0.078 & \multicolumn{2}{|c|}{ (I6) } \\
\hline \multirow{2}{*}{$\begin{array}{l}\text { Mother at delivery } \\
\text { Carotenoids }(\mu \mathrm{g} / \mathrm{l})\end{array}$} & & & & & & \\
\hline & \multicolumn{2}{|c|}{ (6) } & \multicolumn{2}{|c|}{ (8) } & \multicolumn{2}{|c|}{$(9)$} \\
\hline Vitamin A $(\mu \mathrm{g} / 1)$ & \multicolumn{2}{|c|}{ (7) } & $244^{\mathrm{a}}$ & 33 & $309^{\mathrm{a}}$ & \\
\hline \multicolumn{7}{|l|}{ Cord } \\
\hline Carotenoids $(\mu \mathrm{g} / \mathrm{l})$ & \multicolumn{2}{|c|}{ (4) } & \multicolumn{2}{|c|}{ (7) } & $484^{\mathrm{a}}$ & 203 \\
\hline Vitamin A $(\mu \mathrm{g} / 1)$ & $135^{a *}$ & 15 & $195^{\mathrm{a}}$ & & $232^{\mathrm{b}}$ & \\
\hline
\end{tabular}

a, Mean values with unlike superscript letters in horizontal rows were significantly different $(P<0 \cdot 05)$.

* Mean values were significantly different from those of the mother at delivery $(P<0.05)$.

Table 3. Changes in haemoglobin values $(g / l)$ in pregnant low-income Indian women (Mean values with their standard errors; no. of subjects in parentheses)

\begin{tabular}{|c|c|c|c|c|c|c|c|c|c|c|c|c|c|}
\hline $\begin{array}{l}\text { Gestational age } \\
\text { (weeks)... }\end{array}$ & \multicolumn{2}{|c|}{$<12$} & \multicolumn{2}{|c|}{$14-16$} & \multicolumn{2}{|c|}{$18-20$} & \multicolumn{2}{|c|}{$22-24$} & \multicolumn{2}{|c|}{$26-28$} & \multicolumn{2}{|c|}{$30-32$} & $34-38$ \\
\hline Group & Mean & $S E$ & Mean & $\mathrm{sE}$ & Mean & $\mathrm{SE}$ & Mean & SE & Mean & SE & Mean & $\mathrm{SE}$ & Mean SE \\
\hline Overall basal & $\begin{array}{l}114 \\
\quad(23\end{array}$ & & $\begin{array}{l}109 \\
\quad 46\end{array}$ & $2 \cdot 1$ & 108 & (29) & \multicolumn{2}{|c|}{$(20)$} & \multicolumn{2}{|c|}{$\begin{array}{l}96^{*} 2.5 \\
(15)^{2}\end{array}$} & \multicolumn{2}{|c|}{${ }_{(3)}{ }^{2.9}$} & $111{ }_{(7)^{3 \cdot 4}}^{3 \cdot 4}$ \\
\hline Iron supplementation & \multicolumn{2}{|c|}{ - } & \multicolumn{2}{|c|}{-} & $\begin{array}{l}103 \\
(1\end{array}$ & $2 \cdot 8$ & $\begin{array}{l}109 \\
(20\end{array}$ & $2 \cdot 9$ & $\begin{array}{l}104 \\
(25\end{array}$ & $3 \cdot 9$ & $\begin{array}{l}102 \\
(21\end{array}$ & $2 \cdot 8$ & $\begin{array}{ll}111 & 2-2 \\
(28) & \end{array}$ \\
\hline $\begin{array}{l}\text { Fe and vitamin } A \\
\text { supplementation }\end{array}$ & - & & - & & $\begin{array}{l}108 \\
(2\end{array}$ & $2 \cdot 1$ & $\begin{array}{l}104 \\
(32\end{array}$ & & $\begin{array}{r}109 \dagger \\
\quad(47\end{array}$ & $2 \cdot 1$ & $\begin{array}{l}105 \\
(45\end{array}$ & $1-8$ & $\begin{array}{c}1102 \cdot 4 \\
(42)\end{array}$ \\
\hline
\end{tabular}

* Mean value was significantly different from those at $<12$ and $34-38$ weeks of gestation $(P<0 \cdot 05)$.

$\uparrow$ Mean value was significantly different from overall basal level $(P<0 \cdot 05)$.

treated with vitamin $\mathrm{A}$, there was a further increase in haemoglobin values at the same gestational age (109 (SE $2 \cdot 1) \mathrm{g} / \mathrm{l})$, and this increase was statistically significant. However, no statistical difference was found at other gestational ages.

\section{DISCUSSION}

The carotenoid concentration in the plasma of NPNL women was not significantly different from that of pregnant women at 12-14 weeks of gestation. Carotenoid levels in the present study increased with the progress of gestation. Earlier workers had also observed the same pattern (Bodansky et al. 1943; Venkatachalam et al. 1962; Basu \& Arulanantham, 1973; Ette \& Ibeziako, 1984). In general, carotenoid values are expected to reflect immediate intakes of carotenoids and do not represent overall vitamin A status of the pregnant women (Gal \& Parkinson, 1974). 
The fluctuations in plasma vitamin A levels during gestation confirm the longitudinal observations of earlier workers. A general decline in plasma vitamin A during early gestation compared with the NPNL state (Bodansky et al. 1943; Lübke \& Finkbeiner, 1958; Gal \& Parkinson, 1972; Basu \& Arulanantham, 1973), a mid-gestation increase (Gal \& Parkinson, 1972) and a tendency to decline towards term (Darby et al. 1953; McGanity et al. 1969) were reported. This decrease may be because of poor nutritional status of the mother, since a sharp decline is not observed in pregnant Western women (Gal \& Parkinson, 1972; Morse et al. 1975) and in Indian women of high socio-economic status (Shah et al. 1987). The retinol concentrations of fetal liver have been reported to be lower in the low-income groups than those in the high socio-economic groups for the corresponding gestational age, indicating that the fetal vitamin A stores depend on maternal vitamin A status (Shah et al. 1987).

The decline in plasma vitamin A during the third trimester of pregnancy may also be due to the increased transfer of vitamin A across the placenta. The increase in carotenoid levels with gestational age may be due to increased absorption during the later stages of pregnancy. Since the concentrations of $\beta$-carotene and vitamin $E$ increase with the progress of gestation, the fall in serum retinol levels cannot be attributed to haemodilution (Moore, 1957).

The typical gestational age-dependent changes in plasma vitamin A may be due to the various hormones and metabolic signals that mobilize the vitamin $\mathrm{A}$ to meet increased demands during pregnancy. This is reflected in the increased levels of plasma vitamin A during mid-gestation. However, the meagre stores of some women may not be sufficient to cope with the demand and, hence, the plasma vitamin A tends to decline towards term. It has been observed in another city from our country, that the plasma vitamin A levels of pregnant women from high socio-economic groups did not show a significant difference between the three trimesters of pregnancy, whereas those of the low-income group did (Shah et al. 1987).

\section{Effect of supplementation on plasma vitamin $A$}

Reports in the literature have uniformly indicated the beneficial effects of vitamin A supplementation during pregnancy. Previous work has shown that whether vitamin A is administered in doses exceeding the safe limit set by the World Health Organization (Lund \& Kimble, 1943; Neuweiler, 1943; Lewis et al. 1947) or given in divided doses throughout pregnancy (Vijayalakshmi \& Lakshmi, 1983) or multi-vitamin tablets (Gal \& Parkinson, 1974; Baker et al. 1975), there was a significant increase in maternal plasma vitamin A in the third trimester. Another study showed that when $2400 \mu \mathrm{g}$ vitamin A/d was given to women from 30 weeks of gestation until term, an increase in maternal vitamin A levels at delivery was observed when compared with the unsupplemented group (Howells et al. 1986).

In the present study, a supplement of $1800 \mu \mathrm{g}$ vitamin $\mathrm{A} / \mathrm{d}$ significantly increased vitamin $A$ values at term. The time of commencement of this treatment seemed not to affect this outcome, but at this level of supplementation, 12 weeks seems to be necessary for bringing about a change in plasma vitamin A.

One of the striking observations, perhaps made for the first time here, is that a short period of withdrawal ( $6-8$ weeks) subsequent to a longer period of supplementation $(>12$ weeks) did not in any way reduce the beneficial effects of supplementation (Table 1). This is an important aspect from the point of view of practical application.

The results of the present study indicate that the mean vitamin A values of cord samples in the untreated group were lower than maternal values. The results of studies on the beneficial effects of supplementation on cord retinol levels have been controversial due to 
differences in experimental design. While some found an increase (Venkatachalam et al. 1962; Baker et al. 1975), others found no such effect (Lewis et al. 1947; Vijayalakshmi \& Lakshmi, 1983). Results obtained from the present study agree with those of earlier investigators (Venkatachalam et al. 1962; Baker et al. 1975) who found an increase after supplementation. Short-term supplementation had no effect on cord vitamin $A$ in the present study, which agrees with the findings of an earlier study (Howells et al. 1986).

The values for mean birth weights of neonates observed in the control group in the present study are in agreement with those reported earlier from this Institute (Iyengar \& Rajalakshmi, 1975). Supplementation with vitamin A did not improve the birth weights, as was also shown in other studies (Jayarao \& Shatrugna, 1976; Howells et al. 1986).

\section{Effect of supplementation on haemoglobin levels}

It has been suggested that changes in erythrocyte and plasma volume during pregnancy are the two factors that determine the trend of changes in haemoglobin levels (Hytten \& Leitch, 1971). The changes in plasma and erythrocyte volume do not occur synchronously during pregnancy. Plasma volume tends to show an increase from the early weeks until week 32 of pregnancy, after which it tapers off. The rise in erythrocyte volume starts later and continues until term (Hytten \& Leitch, 1971; Peck \& Arias, 1979). The increase in haemoglobin values with Fe supplementation shows that reduced values may be due to $\mathrm{Fe}$ deficiency rather than being entirely a physiological phenomenon (McFee, 1979). In the present study similar results were obtained with $\mathrm{Fe}$ supplementation, but the rise in haemoglobin values at $26-28$ weeks with $\mathrm{Fe}$ and vitamin $\mathrm{A}$ supplementation was greater than that with Fe supplementation alone.

These results are only suggestive that supplementation with vitamin $\mathrm{A}$ along with $\mathrm{Fe}$ brings about a marginal benefit in haemoglobin status. On the other hand, previous workers (Vijayalakshmi \& Lakshmi, 1983; Vijayalakshmi \& Devadas, 1985) found a substantial improvement after supplementation with vitamin $\mathrm{A}$.

The significance and mechanisms by which vitamin A improves the haematological variables are not clear. In a study carried out in rats (Mejia et al. 1979), vitamin A deficiency was found to result in accumulation of radio-labelled $\mathrm{Fe}$ in the liver, with reduced distribution in erythrocytes. It was suggested that vitamin $\mathrm{A}$ is required for the mobilization and utilization of Fe for haemoglobin synthesis.

The authors are grateful to Dr Leela Raman, Deputy Director, National Institute of Nutrition, Hyderabad, for her encouragement. The vitamin A tablets were a gift from Roche India Ltd.

\section{REFERENCES}

Baker, H., Frank, O., Thomson, A. D., Langer, A., Munves, E. D., Angelis, B. \& Kaminetzky, H. A. (1975). Vitamin profile of 174 mothers and new borns at parturition. American Journal of Clinical Nutrition 28, 59-65.

Basu, S. R. J. \& Arulanantham, R. (1973). A study of serum protein and retinol levels in pregnancy and toxaemia of pregnancy in women of low socio-economic status. Indian Journal of Medical Research 61, 589-595.

Bodansky, O., Lewis, J. M. \& Lillienfeld, M. C. C. (1943). The concentration of vitamin A in the blood plasma during pregnancy. Journal of Clinical Investigation 22, $643-647$.

Dacie, J. V. \& Lewis, S. M. (editors) (1975). In Practical Haematology, 5th ed., p. 32. London: Churchill Livingstone.

Darby, W. J., McGanity, W. J., Martin, M. P., Bridgeforth, E., Densen, P. M., Kaser, M. M., Ogle, P. J., Newbill, J. A., Stockell, A., Ferguson, M. E., Touster, O., McClellan, G. S., William, C. \& Cannon, R. O. (1953). The Vanderbilt cooperative study of maternal and infant nutrition. Journal of Nutrition 51, 565-597.

Dixit, D. T. (1966). Night blindness in third trimester of pregnancy. Indian Journal of Medical Research 54, $791-795$

Ette, S. I, \& Ibeziako, P. A. (1984). Vitamin A levels in pregnant Nigerian women and new born. Journal of Obstetrics and Gynaecology of India 34, 780-784. 
Gal, I. \& Parkinson, C. E. (1972). Variations in the pattern of maternal serum vitamin A and carotenoids during human reproduction. International Journal for Vitamin and Nutrition Research 42, 565-575.

Gal, I. \& Parkinson, C. E. (1974). Effects of nutrition and other factors on pregnant women's serum vitamin A levels. American Journal of Clinical Nutrition 27, 688-695.

Gopalan, C. \& Jayarao, K. S. (1972). Nutrition in pregnancy. Tropical Doctor 2, 29-33.

Howells, D. W., Haste, F., Rosenberg, D., Brown, I. R. F. \& Brooke, O. G. (1986). Investigation of vitamin A nutrition in pregnant British Asians and their infants. Human Nutrition: Clinical Nutrition 40 C, 43-50.

Hytten, F. E. \& Leitch, I. (1971). Physiology of Human Pregnancy, 2nd ed., p. 30. Oxford: Blackwell Scientific Publications,

Iyengar, L. \& Rajalakshmi, K. (1975). Effect of folic acid supplement on birth weights of infants. American Journal of Obstetrics and Gynaecology 122, 332-336.

Jayarao, K. S. \& Shatrugna, V. (1976). Effect of vitamin A supplementation on plasma progesterone levels in pregnancy. Indian Journal of Medical Research 64, 1261-1266.

Lewis, J. M., Bodansky, O., Lillienfeld, M. C. C. \& Schneider, M. (1947). Supplements of vitamin A and of carotene during pregnancy. American Journal of Diseases in Childhood 73, 143-150.

Lübke, F. \& Finkbeiner, H. (1958). Beitrag zum Verhalten des Vitamin-A- und $\beta$-Carotin-Spiegels in der Gravidät, unter der Geburt und im Wochenbett. Internationale Zeitschrift für Vitaminforschumg $29,45-68$.

Lund, C. J. \& Kimble, M. S. (1943). Vitamin A during pregnancy, labor and the puerperium. American Journal of Obstetrics and Gynaecology 46, 486-501.

McFee, J. G. (1979). Iron metabolism and iron deficiency during pregnancy. Clinical Obstetrics and Gynaecology 22, 799-808.

McGanity, W. J., Little, H. M., Fugelman, A., Jennings, L., Calhoun, C. \& Dawson, E. B. (1969). Pregnancy in the adolescent. American Journal of Obstetrics and Gynaecology 103, 773-788.

Mejia, L. A., Hodges, R. E. \& Rucker, R. B. (1979). Role of vitamin A in the absorption, retention and distribution of iron in the rat. Journal of Nutrition 109, 129-137.

Moore, T. (1957). Vitamin A, pp. 237-249. Amsterdam: Elsevier.

Morse, E. H., Clarke, R. P., Keyser, D. E., Merrow, S. B. \& Bee, D. E. (1975). Comparison of the nutritional status of pregnant adolescents with adult pregnant women. 1. Biochemical findings. American Journal of Clinical Nutrition 28, 1000-1013.

Neuweiler, W. (1943). Karotin- und Vitamin A-resorption aus der Plazenta. Internationale Zeitschrift für Vitaminforschung 13, 275-280.

Panth, M., Yashodara, P. \& Sivakumar, B. (1986). Effect of supplementary vitamin A on plasma vitamin A levels in pregnancy. Proceedings of the Nutrition Society of India 32, 121-125.

Peck, T. M. \& Arias, F. (1979). Haematologic changes associated with pregnancy. Clinical Obstetrics and Gynaecology 22, 785-798.

Shah, R. S., Rajalakshmi, R., Bhatt, R. V., Hazra, M. N., Patel, B. C. \& Swamy, N. B. (1987). Liver stores of vitamin $\mathrm{A}$ in human fetuses in relation to gestational age, fetal size and maternal nutritional status. British Journal of Nutrition 58, 181-189.

Tiews, J. \& Zentz, C. (1967). Die Mikrobestimmung von vitamin A in Blutserum und Leberpunktaten mit FeCl in Acetylchlorid. Internationale Zeitschrift für Vitaminforschung 37, 307-314.

Venkatachalam, P. S., Belavady, B. \& Gopalan, C. (1962). Studies on vitamin A nutritional status of mothers and infants in poor communities of India. Journal of Pediatrics 61, 262-268.

Vijayalakshmi, P. \& Devadas, R. P. (1985). Role of vitamin A in haemopoiesis. XIIIth International Congress of Nutrition, Brighton. Abstracts of Original Communications. p. 144 (Abstr.).

Vijayalakshmi, P. \& Lakshmi, R. N. (1983). Effect of vitamin A and iron supplementation on serum levels of these nutrients among expectant mothers. Indian Journal of Nutrition and Dietetics 20, 149-152. 